\title{
Hormonal Regulation of the Glycogen/Glucose Balance in Xenopus laevis
}

\author{
D.R. Atar-Zwillenberg, M. Atar, and U.M. Spornitz
}

Institute of Anatomy of the University of Basel, Division of Electron Microscopy, 4056 Basel, Switzerland

\section{Background}

The South African clawed toad Xenopus laevis (Daudin) was used to study the hormonal regulation of glycogen metabolism in amphibians. Preliminary investigations had shown that the liver glycogen in this animal is not only very high but also very stable under physiologic conditions. It was the aim of this study to analyze systematically the effects of hormones and various substances relevant to the glycogen/glucose balance in the adult males and females.[1]

\section{$\underline{\text { Methods }}$}

Insulin, glucagon, epinephrine, cortisol, human chorionic gonadotropin (HCG), alloxan, and streptozotocin were administered to the animals. Liver and muscle glycogen contents, blood glucose and lipid levels were subsequently determined and compared to control values. Additionally we investigated ultrastructural changes in the hepatocytes induced by the different treatments.[2]

\section{$\underline{\text { Results }}$}

With one exception, the liver glycogen content was neither reduced nor augmented by the hormone applications. HCG induced spawning led to the vitellogenic response and markedly reduced the liver glycogen in females, whereas the male liver glycogen slightly increased. Muscle glycogen contents were not affected by any of the treatments. Significant differences were found in the blood glucose level, not only between the different hormone applications but also between the sexes. In males, the blood glucose concentration remained unchanged by the various treatments except after application of epinephrine and cortisol, which led to elevated levels. In females, insulin caused a marked decrease, glucagon, cortisol and epinephrine an increase of the blood glucose. Lipid levels were elevated in both sexes after application of epinephrine and cortisol.[3]

\section{Conclusions}

The liver glycogen is extremely stable in Xenopus laevis. Only the production of yolk ingredients (vitellogenic response of the female) causes a marked utilization of glycogen.

Since blood glucose levels are elevated in epinephrine and cortisol treated toads of both sexes without the liver glycogen being affected, we believe that protein and lipid metabolism are generally involved in the maintenance and the surge of blood glucose levels.[4]

\section{$\underline{\text { References }}$}

[1] U.M. Spornitz and G. Morson (1992). Acta Anat. 143:168.

[2] W. Hanke and U. Neumann (1972). Gen. Comp. Endocrinol. Suppl. 3: 198 -208.

[3] S. Merkle (1989). J. Comp. Physiol. B 159: 473-480.

[4] C. Woof and P.A. Janssens (1978). Gen. Comp. Endocrinol. 36: 346-359. 


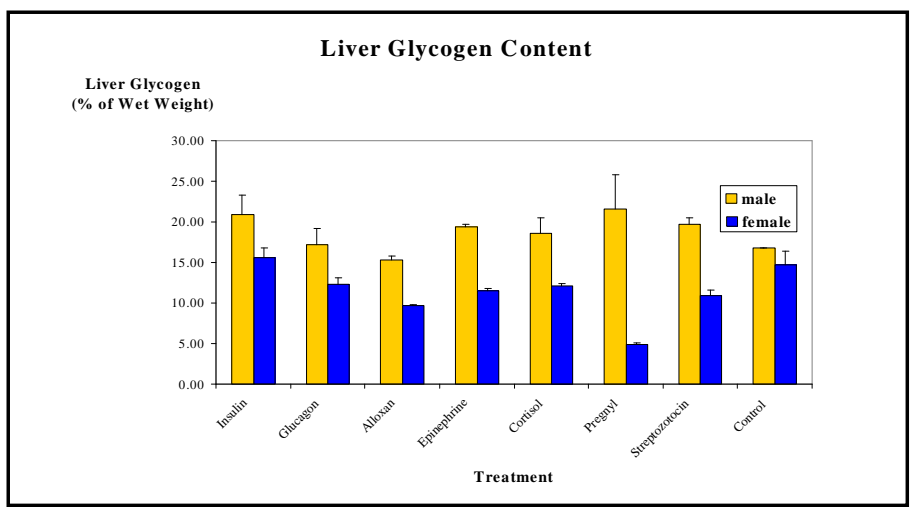

Fig. 1 Liver glycogen contents of adult Xenopus laevis males and females after different hormone applications. $\mathrm{n}=3$, mean \pm SEM

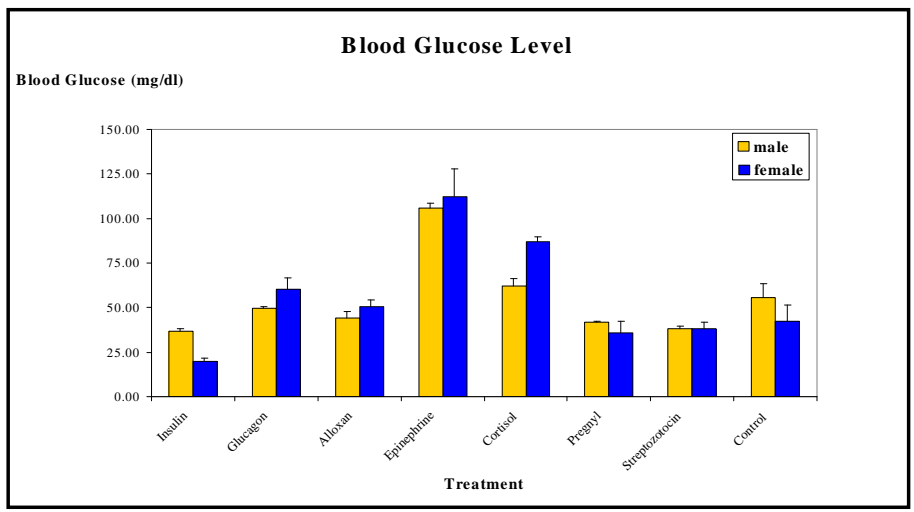

Fig. 2 Blood glucose levels of adult Xenopus laevis males and females after different hormone applications. $\mathrm{n}=3$, mean \pm SEM
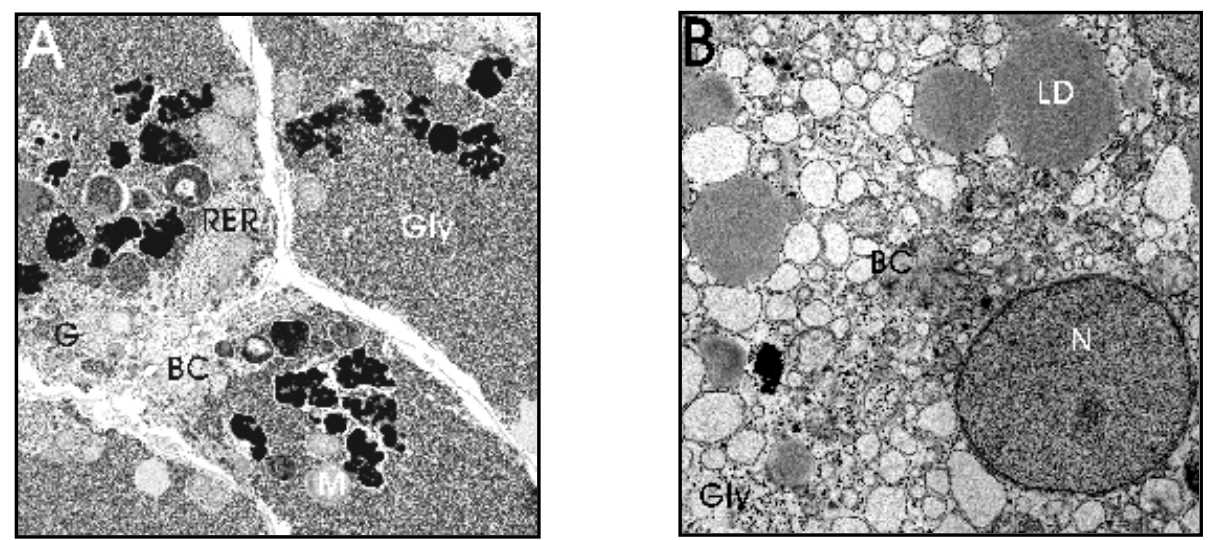

Fig. 3 The effects of hormones on the ultrastructure of Xenopus laevis hepatocytes. A Hepatocytes taken from a glucagon treated male. Note the abundance of glycogen. Mag. x 3472. B Hepatocytes taken from a HCG treated female. The liver glycogen has dropped to about $5 \%$ as compared to 15 $\%$ in control animals. Mag. x 3472. $\mathrm{BC}=$ bile canaliculus, $\mathrm{G}=$ Golgi apparatus, Gly = glycogen, $\mathrm{LD}$ = lipid dropt, $\mathrm{M}=$ mitochondrium, $\mathrm{N}$ = nucleus, $\mathrm{RER}=$ rough endoplasmic reticulum 